\title{
Structural and molecular conservation of glucagon-like peptide-1 and its receptor confers selective ligand-receptor interaction
}

\section{Mi Jin Moon ${ }^{1}$, Sumi Park ${ }^{1}$, Dong-Kyu Kim ${ }^{1}$, Eun Bee Cho ${ }^{1}$, Jong-lk Hwang ${ }^{1}$, Hubert Vaudry ${ }^{2}$ and Jae Young Seong ${ }^{*}$}

Graduate School of Medicine, Korea University, Seoul, Republic of Korea

2 INSERM U982, Laboratory of Neuronal and Neuroendocrine Differentiation and Communication, University of Rouen, Mont-Saint-Aignan, France

Edited by:

Billy K. Chow, University of Hong

Kong, China

\section{Reviewed by:}

Joao Carlos Dos Reis Cardoso,

University of Algarve, Portugal

Charlier Dominique Thierry, University

of Liege, Belgium

\section{*Correspondence:}

Jae Young Seong, Graduate School of Medicine, Korea University, Seoul

136-705, Republic of Korea.

e-mail: jyseong@korea.ac.kr
Glucagon-like peptide-1 (GLP-1) is a major player in the regulation of glucose homeostasis. It acts on pancreatic beta cells to stimulate insulin secretion and on the brain to inhibit appetite. Thus, it may be a promising therapeutic agent for the treatment of type 2 diabetes mellitus and obesity. Despite the physiological and clinical importance of GLP-1, molecular interaction with the GLP-1 receptor (GLP1R) is not well understood. Particularly, the specific amino acid residues within the transmembrane helices and extracellular loops of the receptor that may confer ligand-induced receptor activation have been poorly investigated. Amino acid sequence comparisons of GLP-1 and GLP1R with their orthologs and paralogs in vertebrates, combined with biochemical approaches, are useful to determine which amino acid residues in the peptide and the receptor confer selective ligand-receptor interaction. This article reviews how the molecular evolution of GLP-1 and GLP1R contributes to the selective interaction between this ligand-receptor pair, providing critical clues for the development of potent agonists for the treatment of diabetes mellitus and obesity.

Keywords: GLP-1, GLP1R, G protein-coupled receptors, evolution, paralog, ortholog, ligand-receptor interaction

\section{INTRODUCTION}

Glucagon-like peptide-1 (GLP-1) is an intestinal incretin released in response to nutrient ingestion that stimulates insulin secretion in a glucose-dependent manner. The insulinotropic effect of GLP-1 on the pancreas has been demonstrated to be preserved in animal models of diabetes by stimulating insulin exocytosis (Shen et al., 1998; Drucker, 2001; MacDonald et al., 2002), and promoting insulin biosynthesis (Fehmann and Habener, 1992; Perfetti and Merkel, 2000; Moon et al., 2011). Recently, direct effects of GLP-1 on growth, survival (Xu et al., 1999; Stoffers et al., 2000; List and Habener, 2004), and differentiation of $\beta$-cells have been reported (Drucker, 2003). Beside its insulinotropic effects, GLP-1 inhibits glucagon (GCG) secretion in pancreatic $\alpha$-cells (Nauck et al., 2002), attenuates gastric emptying, and ameliorates glucose excursion in the gastrointestinal tract (Nauck et al., 2002).

GLP-1 exerts its action through the G protein-coupled receptor (GPCR), GLP1R. This receptor belongs to the class B (or secretin-like) GPCR family. This GPCR family has only 15 members in humans and is characterized by a relatively long $\mathrm{N}$-terminal extracellular domain (ECD) containing six conserved Cys residues that form a constraint structure necessary for ligand binding

Abbreviations: Bpa, $p$-benzoyl-L-phenyl alanine; CRFR, CRF receptor; Cys, cysteine; ECD, extracellular domain; ECL, extracellular loop; ER, endoplasmic reticulum; GCG, glucagon; GCGR, glucagon receptor; GIP, glucose-dependent insulinotropic polypeptide; GIPR, GIP receptor; GLP-1, glucagon-like peptide1; GLP1R, GLP-1 receptor; GPCR, G protein-coupled receptor; PAC1R, PACAP receptor; PTHR, PTH receptor; TMH, transmembrane helix.
(Couvineau et al., 2004). GLP1R is mainly expressed in pancreatic $\beta$-cells, and upon stimulation by GLP-1, it induces the accumulation of cAMP and the influx of intracellular calcium which accelerate insulin release from secretory granules (Drucker et al., 1987; Fehmann et al., 1995).

GLP-1 and GLP1R are also expressed in the central nervous system. GLP-1 is synthesized largely in the brainstem and transported along axonal networks to diverse brain regions, including the hypothalamus (Vrang et al., 2007; Hisadome et al., 2010). GLP1R is expressed in cerebral cortex, hypothalamus, hippocampus, thalamus, caudate-putamen, and globus pallidum (Alvarez et al., 2005). In the brain, GLP-1 is known to reduce appetite, leading to significant reductions in body weight (Zander et al., 2002). In addition, GLP-1 is likely neuroprotective and involved in neurite growth and spatial learning ability in the brain (During et al., 2003; Perry et al., 2007).

Due to its combined beneficial effects, GLP-1 has been identified as a potential therapeutic agent for the treatment of diabetes mellitus and obesity. However, the molecular mechanisms leading to high affinity ligand-receptor binding and receptor activation have not been fully understood. Studies using alanine scanning mutagenesis, substitution/modification, and chimeric peptide construction of GLP-1 have explored the bioactive motifs of GLP-1(Adelhorst et al., 1994; Gallwitz et al., 1994; Hinke et al., 2004), yet none have been able to identify the mechanism through which individual residues in the peptide interact with residues in the receptor. Recent studies using X-ray crystallography have demonstrated that residues in the central $\alpha$-helical region of GLP-1 
interact with residues in the N-terminal ECD of GLP1R (Runge et al., 2008; Underwood et al., 2010). However, as ligand-induced receptor activation is mainly governed by interactions between residues in the $\mathrm{N}$-terminus of the peptide and residues within the transmembrane helices (TMH) and extracellular loops (ECL) of the receptor (Thorens et al., 1993; During et al., 2003), this crystal structure only accounts for the peptide binding to the ECD of the receptor. Indeed, virtually no progress has been made in exploring the receptor binding sites for the $\mathrm{N}$-terminal moiety of the peptide which is responsible for ligand-induced receptor activation.

Peptide ligands and their receptors have become diversified through evolutionary processes that ultimately yield families of related, yet distinct, peptides and receptors (Hoyle, 1999; Cho et al., 2007; Lee et al., 2009; Kim et al., 2011, 2012). Specific diversification of peptides, conservation within orthologs but variation among paralogs, would often confer the selective interaction with their cognate receptors, allowing discrimination of paralogous receptors (Acharjee et al., 2004; Wang et al., 2004; Li et al., 2005). Thus, amino acid sequence comparison of the peptide and receptor with their orthologs and paralogs, along with mutational mapping approaches, are useful tools helping to determine specific residues in the peptide ligands and receptors that are essential for maintaining selective ligand-receptor interaction. Indeed, ligand binding domains identified in mammalian receptors are highly conserved in orthologous non-mammalian receptors, indicating that there is high evolutionary selection pressure to maintain selectivity for their ligands (Acharjee et al., 2004; Wang et al., 2004; Li et al., 2005). Recently, we reported that evolutionarily conserved amino acid residues in GLP- 1 and core domains of the GLP1R confer selective ligand-receptor interaction and receptor activation (Moon et al., 2010, 2012). This article reviews how the molecular evolution of GLP-1 and GLP1R contributes to acquiring high affinity interaction between this peptide ligand and receptor.

\section{GENERAL STRUCTURE OF GLP-1 AND ITS FAMILY PEPTIDES}

GLP-1 is a product of the GCG gene which encodes a common GCG-GLP-1-GLP-2 precursor. All three peptides are encoded by different exons of the GCG gene, raising the possibility of exon duplications during early vertebrate evolution (Sherwood et al., 2000). The GCG gene produces one or two mature peptides by a tissue-specific alternative post-translational process (Kieffer and Habener, 1999; Irwin, 2001, 2009). For instance, in pancreatic $\alpha$ cells mature GCG, but not GLP-1 and GLP-2, is produced. In intestinal L cells, however, mature GLP-1 and GLP-2, but not GCG, are generated. One GLP-1 paralog is the glucose-dependent insulinotropic polypeptide (GIP) which is independently encoded by the GIP gene (McIntosh et al., 2009). GLP-1 and GIP share a high degree of amino acid sequence identity, particularly in their $\mathrm{N}$-terminal moiety, and function similarly by inducing insulin secretion from $\beta$-cells. However, these peptides act through distinct yet related receptors, GLP1R and GIP receptor (GIPR), respectively. In addition, albeit absent in mammals, another GLP1 paralog is exendin, which was first discovered in Gila monsters (Heloderma suspectum; Göke et al., 1993). Recently, the full-length and/or partial cDNAs for exendin were characterized in a few species, such as Xenopus, chicken, and Gila monster (Irwin and Prentice, 2011). Although the receptor for exendin has not yet been identified in non-mammals, exendin exhibits high affinity binding for mammalian GLP1R (Göke et al., 1993). Recent evidence suggests that the GCG, GIP, and exendin genes were generated by genome duplication events during early vertebrate evolution, as these genes are flanked by similar neighboring genes in the genomes of vertebrates (Irwin, 2002; Irwin and Prentice, 2011).

GLP-1 and its family peptides are $30 \sim 40$ amino acids in length and share similarities in amino acid sequence and secondary structure. All these peptides tend to be disordered in aqueous solutions but exhibit a marked propensity to form $\alpha$-helices under mild ambient conditions, such as in the presence of organic solvents or lipids (Braun et al., 1983; Gronenborn et al., 1987; Thornton and Gorenstein, 1994; Inooka et al., 2001; Neidigh et al., 2001; Chang et al., 2002; Tan et al., 2006; Alana et al., 2007), or upon crystallization (Sasaki et al., 1975). It is now well known that the N-terminal domains of GLP-1-related peptides form a random coil structure, while the central parts of these peptides have an $\alpha$-helical structure. In addition, hydrophobic amino acids at positions 6 and 10, and a short-chain polar amino acid at position 7 form a helix $\mathrm{N}$-capping motif through hydrophobic interaction and hydrogen bonding (Neumann et al., 2008). This capping motif is believed to introduce a specific local fold that facilitates receptor activation upon peptide-receptor binding (Neumann et al., 2008).

The N-terminus of GLP- 1 and its family peptides share a high degree of sequence identity (Figure 1). Particularly, $\mathrm{Gly}^{4}$, Thr $/ \mathrm{Ser}^{5}$, $\mathrm{Phe}^{6}$, and Asp/Glu ${ }^{9}$ are conserved across all GLP-1 paralogs. Indeed, alanine scanning of these conserved residues of GLP-1 suggest that positions 4,6 , and 9 are crucial for either maintaining secondary structure of the peptide or for interaction with the receptor (Adelhorst et al., 1994; Gallwitz et al., 1994). His ${ }^{1}$ and $\mathrm{Thr} / \mathrm{Ser}^{7}$ are common for most GLP-1 paralogs except for GIP, which has $\mathrm{Tyr}^{1}$ and $\mathrm{Ile}^{7}$ in these positions. Our recent observation using a chimeric GLP-1/GIP peptide revealed that His/ $/ \mathrm{Trr}^{1}$ and $\mathrm{Thr} / \mathrm{Ile}^{7}$ are responsible for the selective interaction toward GLP1R and GIPR (Moon et al., 2010). The second position of the peptides is highly variable across paralogs, even within orthologs of vertebrates, and it is known to be of lesser importance for receptor binding. This residue can be modified to Ser or another amino acid to confer protection against cleavage by dipeptidyl peptidase IV (Hinke et al., 2002). The third position of the peptides is variable across paralogs but conserved within orthologs. Although the importance of this ortholog-specific third residue in receptor binding or peptide structure is not fully understood, $\mathrm{Glu}^{3}$ of GIP is known to be critical for receptor interaction (Hinke et al., 2003; Gault et al., 2007; Yaqub et al., 2010).

The sequence similarity of the $\alpha$-helix domain of the peptides is not pronounced among GLP-1 paralogs, and there are also many variable residues within orthologs (Figure 1). However, the $\mathrm{Phe}^{22}$, $\mathrm{Ile} / \mathrm{Val}^{23}$, and $\mathrm{Leu}^{26}$ residues that are part of the hydrophobic surface of the $\alpha$-helix are highly conserved among GLP-1 and its paralogs. Interestingly, all these residues are known to interact with highly conserved residues in the ECD of the GLP1R and its paralogs (Parthier et al., 2007; Runge et al., 2008; Underwood et al., 2010). Some ortholog-conserved residues, Glu/Asp ${ }^{15}$ of exendin and GIP, along with $\mathrm{Ala}^{18 / 19}$ and $\mathrm{Lys}^{20}$ of GLP-1, are found to interact with the receptors as was revealed by the peptide-bound 


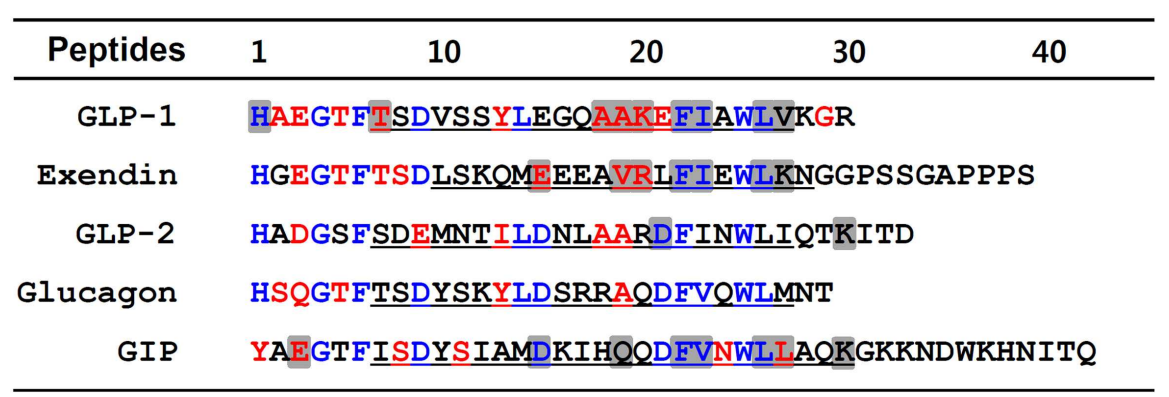

conserved across paralogs conserved within orthologs variable interacting with the receptor
FIGURE 1 | Amino acid sequence alignment of GLP-1 and its

family peptides. Amino acid sequences of human GLP-1, GLP-2, glucagon, GIP, and Gila monster exendin are aligned. Residues in red are conserved sequences within orthologs of vertebrates including mouse, anole, chicken, Xenopus tropicalis, medaka, fugu, tetraodon, stickleback, and zebrafish. The residues colored in blue represent conserved sequences across paralogs. The residues in black are variable sequences. Underlines indicate the $\alpha$-helical conformation. The residues responsible for interaction with their receptor are shaded.
ECD crystal structures (Parthier et al., 2007; Runge et al., 2008; Underwood et al., 2010).

\section{GENERAL STRUCTURE OF CLASS B GPCRS}

The class B GPCR family is composed of 15 members including receptors for VIP, PACAP, secretin, GCG, GLP-1, GLP-2, GHRH, GIP, PTH, calcitonin, calcitonin gene-related peptide, and $\mathrm{CRH}$ (Laburthe et al., 2007). This family shares the general GPCR architecture: seven TMH interconnected by intracellular loops with a C-terminal intracellular domain. Class B GPCRs differ from class A rhodopsin-like GPCRs in the structures of their TMH. The TMH of class B GPCRs do not contain conserved amino acid residues such as Asp/Asn ${ }^{2.50}$ in TMH2, Asn/Asp ${ }^{7.49}$ Pro $^{7.50}$ $\mathrm{x}-\mathrm{x}-\mathrm{Tyr}^{7.53}$ (N/DPxxY) motif in TMH7, Asp/Glu ${ }^{3.49}-\mathrm{Arg}^{3.50}$ Tyr/Trp ${ }^{3.51}$ (D/ERY/W) motif at the junction between TMH3 and intracellular loop 2 that are commonly found in class A rhodopsinlike GPCRs (Oh et al., 2005). Instead, class B receptors share a high degree of amino acid identity in TMH with one another. Further, they possess a large and structured N-terminal ECD of $\sim 120$ residues.

Although no experimentally determined full-length class B receptor structure has been achieved to date, the structure elucidation of individual class B GPCR ECDs represents considerable progress toward a molecular understanding of their action. The first structure of the agonist-bound recombinant N-terminal ECD of the CRH2B receptor has been resolved using NMR (Grace et al., 2004). Six representative ECD structures of the class B family of GPCRs have been determined by X-ray crystallography or NMR spectroscopy in complex with bound ligand: the human VPAC1 receptor (Tan et al., 2006), a subtype of human PACAP receptor $\left(\right.$ PAC1R $_{s}$; Sun et al., 2007), human GIPR (Parthier et al., 2007), human GLP1R (Runge et al., 2008; Underwood et al., 2010), human PTH receptor (PTH1R; Pioszak and Xu, 2008), the human type-1 CRF receptor (CRFR1; Pioszak et al., 2008), and human GLP2R (Venneti and Hewage, 2011).

Class B GPCRs contain N-terminal signal peptides that are cleaved off by the signal peptidase of the endoplasmic reticulum (ER) during the translocation-mediated receptor insertion into the ER membrane. These signal peptides play a crucial role in the membrane expression of receptors (Couvineau et al., 2004;
Alken et al., 2005; Huang et al., 2010). After cleavage of the signal peptide, the N-terminal helix at the beginning of the ECD and four $\beta$-strands forming two antiparallel sheets remain (Figure 2). Three disulfide bonds formed by a set of six Cys residues lock these secondary structural elements together. Cysteine residues are completely conserved across the receptors. The disulfide bond pattern seems to be conserved in all receptors, suggesting a similar three dimensional structure. There are three disulfide bonds between the first and third, the second and fifth, and the fourth and sixth cysteine residues $\left(\mathrm{Cys}^{1}-\mathrm{Cys}^{3}, \mathrm{Cys}^{2}-\mathrm{Cys}^{5}\right.$, $\left.\mathrm{Cys}^{4}{ }^{-} \mathrm{Cys}^{6}\right)$. The first bond $\left(\right.$ Cys $^{1}-$ Cys $^{3}$ ) links the N-terminal $\alpha$-helix to the first $\beta$-sheet. The second $\left(\mathrm{Cys}^{2}-\mathrm{Cys}^{5}\right)$ connects the two $\beta$-sheets, whereas the third disulfide bond $\left(\mathrm{Cys}^{4}{ }^{-} \mathrm{Cys}^{6}\right.$ ) holds the C-terminus of the domain in close proximity to the central $\beta$-sheets (Tan et al., 2006; Parthier et al., 2007, 2009; Sun et al., 2007; Pioszak and Xu, 2008; Pioszak et al., 2008; Runge et al., 2008; Underwood et al., 2010; Venneti and Hewage, 2011).

In addition, this core folding is further stabilized by a salt bridge involving acidic and basic residues flanked by hydrophobic aromatic residues. This fold, called the Sushi domain, is conserved in all class B GPCRs (Grace et al., 2004). Five additional residues, Asp $^{67}, \operatorname{Trp}^{72}$, Pro ${ }^{86}, \mathrm{Gly}^{108}$, and $\operatorname{Trp}^{110}$ in GLP1R and the corresponding residues in class B GPCRs, are conserved. Particularly, Asp and the two Trp residues take part in forming the Sushi domain, suggesting that these residues are crucial for domain stability and ligand binding. The strongly conserved fold observed in the ECD of class B GPCRs suggests that a common mechanism underlies ligand recognition.

The crystal structures of the ligand-bound ECD reveal amino acid residues that interact with their cognate ligands (Parthier et al., 2007; Runge et al., 2008; Underwood et al., 2010). It is of interest to note that many ligand-interacting residues are highly conserved between GLP1R and its paralogs. For instance, $\operatorname{Trp}^{39}$ in the $\alpha 1$-helix, $\operatorname{Asp}^{67}$ in the $\beta 1$-sheet, $\mathrm{Tyr}^{69}$ between the $\beta 1$ - and $\beta 2$-sheet, Arg $^{121}$ near TMH1 of GLP1R, residues 87-90 (Tyr-LeuPro-Trp) between the $\beta 3$ - and $\beta 4$-sheet, $\operatorname{Arg}^{101}$ in the $\beta 4$-sheet, and $\operatorname{Trp}{ }^{112}$ near TMH1 of GIPR are all highly conserved across paralogs (Figure 2). There are also ortholog-specific residues that interact with the peptide ligands, such as Leu ${ }^{32}$ in the $\alpha 1$-helix of GLP1R, and Gly ${ }^{110}$ and His ${ }^{115}$ near TMH1 of GIPR. 


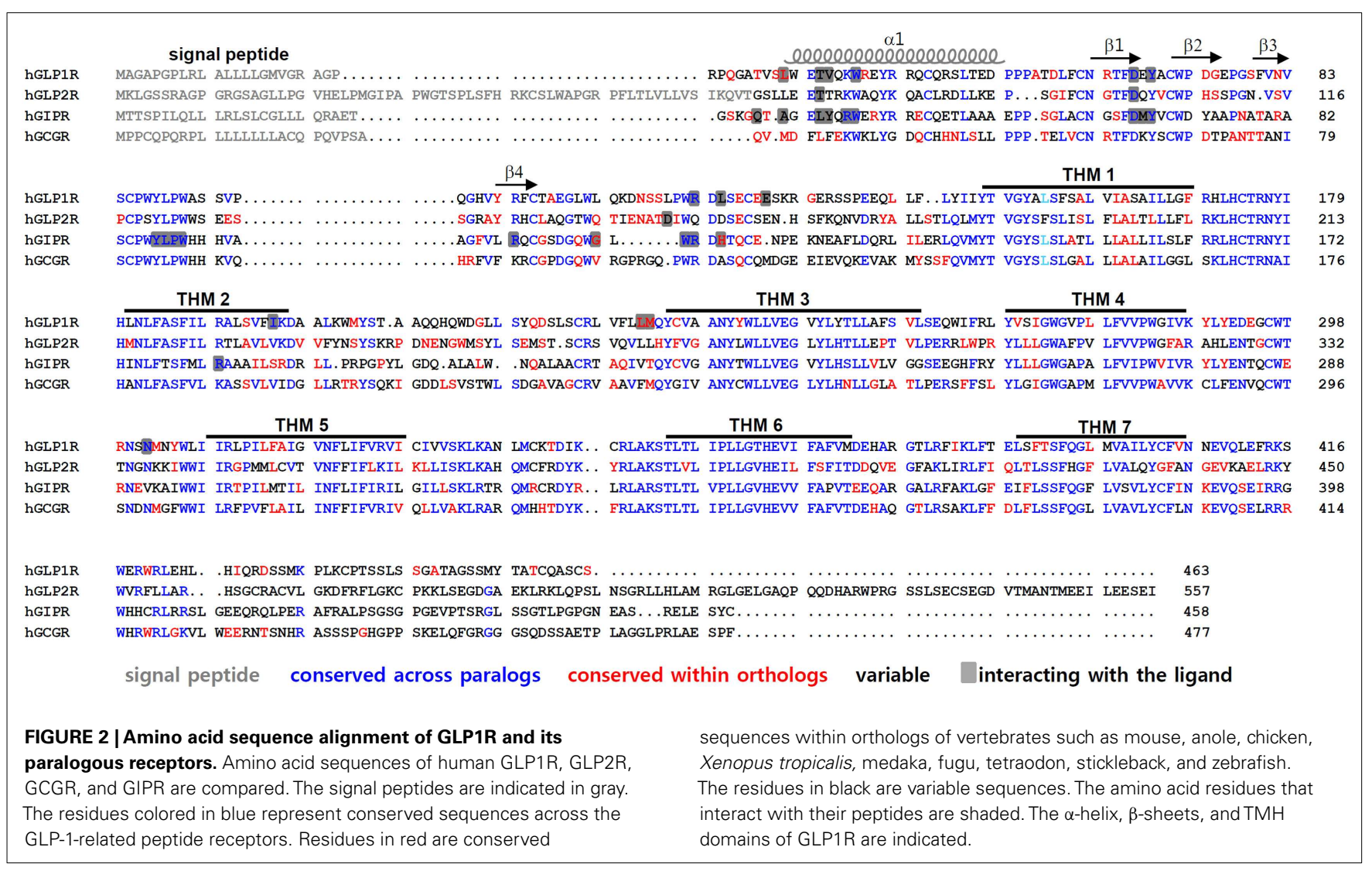

\section{THE TWO-DOMAIN HYPOTHESIS FOR CLASS B GPCR LIGAND BINDING AND ACTIVATION}

Class B GPCRs likely share a similar secondary and tertiary structure with long N-terminal ECD and highly conserved TMHs. The orientation and mechanism of interaction of the peptide with their receptors has been investigated in studies using fragmented peptide/receptor, and chimeric peptides and receptors (Holtmann et al., 1995; Stroop et al., 1995; Bergwitz et al., 1996; Laburthe and Couvineau, 2002; Runge et al., 2003). For instance, the GLP1R ECD itself is able to bind with its peptide ligands (Graziano et al., 1996; Van Eyll et al., 1996; Wilmen et al., 1996, 1997; Runge et al., 2003; Parthier et al., 2007). This binding, however, may not account for ligand-induced receptor activation (Buggy et al., 1995; Holtmann et al., 1995, 1996; Hjorth and Schwartz, 1996; Xiao et al., 2000). The N-terminally truncated exendin(9-39) is unable to activate GLP1R even though it binds to the receptor with an affinity that is comparable to that of wild type exendin (Thorens et al., 1993). In contrast, exendin(1-9), a short N-terminal fragment of exendin, is able to activate GLP1R although its affinity to the receptor is quite low (During et al., 2003). Likewise, the GIP fragment, GIP (7-30), is able to bind to GIPR with high affinity but fails to induce receptor activation. In contrast, GIP (1-14) exhibits a very low affinity toward the receptor but fully activates the receptor at a micromolar concentration (Hinke et al., 2001, 2003; Gault et al., 2007). Thus, the two-domain model explaining ligand binding followed by receptor activation has emerged: the central $\alpha$-helical and C-terminal portion of the peptide binds to the N-terminal ECD of the receptor (Al-Sabah and Donnelly,
2003; Dong et al., 2003; Lopez de Maturana et al., 2003) followed by binding of the $\mathrm{N}$-terminal moiety of the peptide with the core domain - including the TMH and ECL - of the receptor, conferring receptor activation and $\mathrm{G}$ protein coupling (Runge et al., 2003; Lopez de Maturana et al., 2004; Castro et al., 2005; Wittelsberger et al., 2006). The two-domain model is generally consistent with photoaffinity crosslinking studies of several class B receptors. With a few exceptions, photoreactive side chains in the C-terminus of the peptide ligand interact with residues in the ECD of the receptor, whereas photoreactive side chains in the $\mathrm{N}$-terminus of the ligand bind to the TMH domain (Gensure et al., 2001; Assil-Kishawi and Abou-Samra, 2002; Dong and Miller, 2002; Dong et al., 2004). Most recently, strong corroborating evidence for the two-domain model has been obtained by the structural characterization of the isolated ECDs of several class B GPCRs (Grace et al., 2004; Parthier et al., 2007; Sun et al., 2007; Pioszak and Xu, 2008; Pioszak et al., 2008; Runge et al., 2008; Underwood et al., 2010).

\section{MOLECULAR EVOLUTION OF GLP-1 AND GLP1R FOR THEIR SELECTIVE INTERACTION}

Although GLP-1 and its paralogs share a high degree of sequence identity and structural similarly, they generally exhibit specific binding to their own cognate receptors with little cross-reactivity with paralogous receptors (Runge et al., 2003; Moon et al., 2010, 2012). This observation allows us to presume the presence of distinct amino acid residues within each peptide and receptor that allows for the selective interaction with their own partners. Further, these facts indicate that evolutionary selection pressure has 
exerted a specific diversification of peptide and receptor: variation among paralogs but conservation within orthologs. However, there are some exceptional cross-reactivities among paralogous partners. For instance, exendin, a GLP-1 paralog in non-mammals, has a high affinity for the mammalian GLP1R (Göke et al., 1993). Until now, genetic orthologs for GLP1R have not been found in teleost fish, yet teleost fish have two copies of GLP-1 peptides which have been generated by teleost-specific genome duplication (Plisetskaya and Mommsen, 1996; Irwin and Wong, 2005). Interestingly, GLP-1 is able to activate fish GCG receptor (GCGR) orthologs (Yeung et al., 2002; Irwin and Wong, 2005), indicating that fish GCGRs have achieved functional response to GLP-1 through an evolutionary process. These exceptional cross-reactivities provide a unique opportunity to explore the identification of specific amino acid residues in the peptides and receptors responsible for specific ligand-receptor interaction. For instance, amino acid sequence comparison between GLP-1 and exendin allows us to predict which amino acid residues are important for the activation of GLP1R (Moon et al., 2010). Sequence comparison between tetrapod GLP1Rs and fish GCGRs has led to the identification of residues in these receptors that interact with GLP-1 (Moon et al., 2012).

\section{INTERACTION BETWEEN THE $\alpha$-HELIX OF THE PEPTIDE AND THE ECD OF THE RECEPTOR}

The crystal structures of the ligand-bound ECD revealed that GLP1 is a continuous $\alpha$-helix from $\mathrm{Thr}^{7}$ to $\mathrm{Val}^{27}$, with a kink around $\mathrm{Gly}^{16}$. Only the residues between $\mathrm{Ala}^{18}$ and $\mathrm{Val}^{27}$ interact with the ECD. The $\alpha$-helical segment of GLP-1 is amphiphilic, allowing hydrophilic and hydrophobic interactions through opposite faces of the $\alpha$-helix (Underwood et al., 2010). The hydrophilic face of GLP-1 comprises residues Gln ${ }^{17}$, $\mathrm{Lys}^{20}$, Glu ${ }^{21}$, and $\mathrm{Lys}^{28}$, of which only Lys ${ }^{20}$ interacts directly with the ECD by forming a hydrogen bond with the side chain of $\mathrm{Glu}^{128}$. Interestingly, exendin also possesses a basic residue at position $20\left(\mathrm{Arg}^{20}\right)$, allowing interaction with $\mathrm{Glu}^{128}$ of the GLP1R ECD (Runge et al., 2008; Underwood et al., 2010). The hydrophobic face of GLP-1 includes $\mathrm{Ala}^{18}, \mathrm{Ala}^{19}, \mathrm{Phe}^{22}, \mathrm{Ile}^{23}, \mathrm{Leu}^{26}$, and $\mathrm{Val}^{27}$. The hydrophobic residues are exposed toward the complementary hydrophobic binding pocket in the ECD. Particularly, $\mathrm{Phe}^{22}, \mathrm{Ile}^{23}$, and $\mathrm{Leu}^{26}$ of the peptide are found to interact with the highly conserved residues $\mathrm{Val}^{36}, \operatorname{Trp}^{39}, \mathrm{Asp}^{67}, \mathrm{Tyr}^{69}, \mathrm{Arg}^{121}$, and $\mathrm{Leu}^{123}$ in the ECD of GLP1R (Underwood et al., 2010). The contribution of $\mathrm{Phe}^{22}$, $\mathrm{Ile}^{23}$, and $\mathrm{Leu}^{26}$ to GLP1R binding has been demonstrated by Ala substitutions or mutations of these residues (Adelhorst et al., 1994; Wilmen et al., 1997). It is of interest to note that the GLP-1 family peptides exendin, GIP, GLP-2, and GCG also contain hydrophobic residues $\mathrm{Phe}^{22}, \mathrm{Ile} / \mathrm{Va}^{23}$, and $\mathrm{Leu}^{26}$. Further, residues $\operatorname{Trp}^{39}, \mathrm{Asp}^{67}$, $\mathrm{Tyr}^{69}$, and $\mathrm{Arg}^{121}$ in the GLP1R ECD are also highly conserved in GLP2R, GIPR, and GCGR (Parthier et al., 2007; Runge et al., 2008; Underwood et al., 2010; Venneti and Hewage, 2011). This observation suggests that these residues are evolutionarily conserved and likely contribute to the primary binding between the $\alpha$-helix of the peptides and ECD of the receptors. This may also in part account for the cross-interaction of one $\alpha$-helix of the peptide with the ECD of other partners (Parthier et al., 2007; Runge et al., 2008; Underwood et al., 2010). Indeed, this is supported by the observations that chimeric peptides containing the GLP-1 N-terminus with the $\alpha$-helix of GIP or GCG can induce GLP1R activation with a relatively high potency (Runge et al., 2003; Moon et al., 2010). However, the specific interaction of the $\alpha$-helix of the peptide with the ECD of its own receptor may be of higher affinity than those with other related paralogous receptors. For instance, interaction of $\mathrm{Ala}^{19}$ of GLP-1 with GLP1R-specific Leu ${ }^{32}$, and Gln ${ }^{19}$ of GIP with GIPR-specific $\mathrm{Ala}^{32}$, may explain the higher affinity of each peptide toward its own receptor than toward paralogous receptors (Parthier et al., 2007; Underwood et al., 2010).

\section{INTERACTIONS BETWEEN THE N-TERMINUS OF THE PEPTIDE AND THE CORE DOMAIN OF THE RECEPTOR}

Specificity of ligand-receptor binding between a peptide and the corresponding receptor can be further conferred by binding between the $\mathrm{N}$-terminus of the peptide and the receptor core domain. In addition, this interaction allows ligand-induced receptor activation (Thorens et al., 1993; Montrose-Rafizadeh et al., 1997; Hinke et al., 2001, 2003; During et al., 2003; Gault et al., 2007). Therefore, many approaches, such as alanine scanning, photoaffinity labeling, and molecular modeling-based approaches have explored the specific residues within the peptide and receptor responsible for ligand-receptor interaction (Adelhorst et al., 1994; Gallwitz et al., 1994; Xiao et al., 2000; Lopez de Maturana and Donnelly, 2002; Lopez de Maturana et al., 2004; Chen et al., 2009, 2010; Lin and Wang, 2009). Alanine scanning of GLP1R demonstrated that residues found between the TMH2 and ECL1

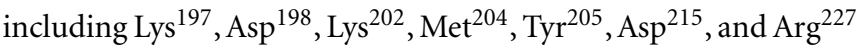
are likely important for the binding of the receptor to the $\mathrm{N}$ terminal moiety of GLP-1, as mutations at these residues lead to a significant decrease in ligand affinity (Xiao et al., 2000; Lopez de Maturana and Donnelly, 2002; Lopez de Maturana et al., 2004). However, these observations did not define how these individual residues interact with in the N-terminal moiety of GLP-1. Further, Ala mutations in these residues can modify the receptor conformation which may interfere with binding to the ligand. Recently, using photoaffinity labeling, Chen et al. (2010) observed that $\mathrm{Tyr}^{205}$ in ECL1 is in close proximity to the $p$-benzoyl-L-phenyl alanine (Bpa) at position 6 of GLP-1. However, the mutation of $\mathrm{Tyr}^{205}$ to Ala in GLP1R does not alter either receptor activity or ligand binding, indicating that $\mathrm{Tyr}^{205}$ is not the direct binding site for the N-terminal moiety of GLP-1. Furthermore, no ligand-bound crystal structure for the core domain of the class B GPCR family is currently available. Thus, our understanding of the molecular mechanism underlying the high affinity interaction between the $\mathrm{N}$-terminal moiety of the peptide and the receptor core domain is primitive.

Recently, by comparing the amino acid sequences of GLP-1 and GLP1R with their orthologs and paralogs in vertebrates, we were able to obtain clues to help determine which amino acid residues may be responsible for ligand-receptor interaction (Moon et al., 2010,2012). Although the GLP-1-related family of peptides shares a similarity in the amino acid sequence at the N-terminal moiety, there are specific, divergent amino acid sequences. For instance, the N-terminus of GLP-1 and its family peptides starts with either $\mathrm{His}^{1}$ (for GCG, GLP-1, GLP-2, and exendin) or $\mathrm{Tyr}^{1}$ (for GIP), and most of the peptides contain Thr at position 7 (GCG, GLP-1, 
and exendin), or Ser (GLP-2); only GIP contains Ile at this position. The first and seventh amino acid residues of each peptide are conserved within orthologs of vertebrate species. Thus, it may be postulated that His/Tyr ${ }^{1}$ or $\mathrm{Thr} / \mathrm{Ile}^{7}$ residues of GLP-1 and GIP confer ligand selectivity to their cognate receptors. Indeed, our recent observation using chimeric GLP-1/GIP peptide reveals that the His/Tyr ${ }^{1}$ and Thr/Ile ${ }^{7}$ residues within these peptides confer differential ligand selectivity toward GIPR and GLP1R, respectively (Moon et al., 2010).

The chimeric GLP1R/GIPR approach together with chimeric GLP-1/GIP peptides offers a new strategy to determine which residues in the core domain are responsible for interacting with His $^{1}$ and Thr $^{7}$ of GLP-1 (Moon et al., 2012). For example, this approach enables us to determine crude motifs in TMH2, ECL1, and ECL2 of GLP1R which are likely to interact with His ${ }^{1}$ and $\mathrm{Thr}^{7}$ of GLP-1. Amino acid sequence comparison of these regions between those of tetrapod GLP1Rs, fish GCGRs, and vertebrate GIPRs further define amino acid residues that tentatively interact with His ${ }^{1}$ and $\mathrm{Thr}^{7}$ of GLP-1. In this case, we searched for residues which are conserved within GLP1R ortholog and fish GCGR but are different from those of GIPRs. We were able to identify Ile ${ }^{196}$ and Lys ${ }^{197}$ of TMH2, and Met ${ }^{233}$ of ECL1, and Asn ${ }^{302}$ and $\mathrm{Met}^{303}$ of ECL2 in GLP1R (Moon et al., 2012). It is noteworthy that fish GCGRs exhibit both a significantly high affinity for GLP-1 (Irwin and Wong, 2005) and these conserved residues, even though other regions are significantly different from tetrapod GLP1Rs (Figure 3). Mutational mapping together with application of chimeric GLP-1/GIP peptides reveals that $\mathrm{His}^{1}$-harboring peptides are sensitive for $\mathrm{Asn}^{302}$ mutations, while $\mathrm{Thr}^{7}$-containing chimeric peptides are highly sensitive for the $\mathrm{Ile}^{196}$ mutation, indicating a possible interaction of $\mathrm{His}^{1}$ and $\mathrm{Thr}^{7}$ of GLP-1 with $\mathrm{Asn}^{302}$ and Ile ${ }^{196}$ of GLP1R, respectively. Indeed, computer-aided molecular modeling showed interaction of $\mathrm{His}^{1}$ with $\mathrm{Asn}^{302}$ and of $\mathrm{Thr}^{7}$ with a binding pocket formed by $\mathrm{Ile}^{196}$, $\mathrm{Leu}^{232}$, and $\mathrm{Met}^{233}$ of GLP1R (Moon et al., 2012). Interestingly, $\mathrm{Asn}^{302}$ is highly conserved at the corresponding position in GCGRs ( $\mathrm{Asn}^{300}$ for human) and GLP2Rs ( $\mathrm{Asn}^{336}$ for human), and these receptors have peptide ligands containing His ${ }^{1}$. In addition, GCGRs that respond to a $\mathrm{Thr}^{7}$-containing peptide ligands have conserved $\mathrm{Val}^{193}$ and $\mathrm{Met}^{231}$ at the corresponding positions of Ile ${ }^{196}$, and $\mathrm{Met}^{233}$ of GLP1R, indicating that these residues may have a contact with $\mathrm{Thr}^{7}$ of GCG. This possibility, however, needs to be further addressed.

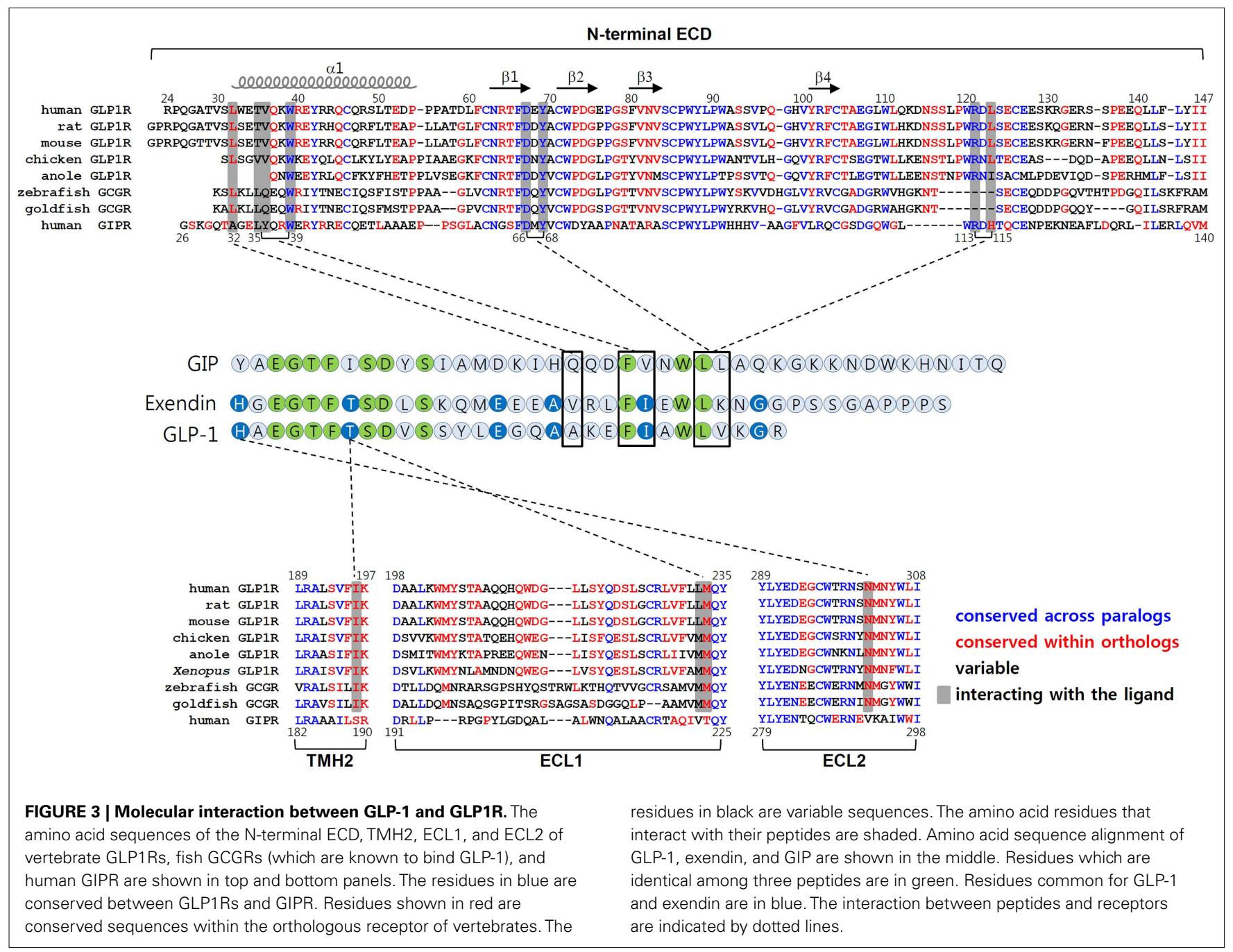




\section{CONCLUSION}

Although GLP-1 may become a promising therapeutic agent for the treatment of type 2 diabetes mellitus and obesity, these peptide agonists cannot be administered orally due to their peptide nature. Thus, orally administered small molecules that regulate GLP1R need to be developed. However, a bottleneck slowing the development of these small molecules is the lack of information regarding the molecular structure of the ligand-bound GLP1R. Unfortunately, the crystal structure of the ligand-bound N-terminal ECD of GLP1R may not fully account for the interaction between peptide ligands and receptors. Rather, it is likely that the seven TMHs and ECLs of the receptors are more critical than the N-terminal ECD for peptide binding and receptor activation. Thus, exploring the domains or amino acid residues within TMHs and ECLs that confer ligand binding and receptor activation may greatly contribute to the design of the molecular model for the peptide ligand-receptor complex. In turn, this would facilitate the development of potent small molecules capable of regulating GLP1R. Determination of ligand-receptor interaction points (either by ligand-bound ECD crystal structure or by biochemical analysis using chimeric peptides and receptors) demonstrates that conserved residues across paralogous peptides tend to interact

\section{REFERENCES}

Acharjee, S., Do-Rego, J. L., Oh, D. Y., Ahn, R. S., Choe, H., Vaudry, H., et al. (2004). Identification of amino acid residues that direct differential ligand selectivity of mammalian and nonmammalian V1a type receptors for arginine vasopressin and vasotocin. Insights into molecular coevolution of Vla type receptors and their ligands. J. Biol. Chem. 279, 54445-54453.

Adelhorst, K., Hedegaard, B. B., Knudsen, L. B., and Kirk, O. (1994). Structure-activity studies of glucagon-like peptide-1. J. Biol. Chem. 269, 6275-6278.

Alana, I., Malthouse, J. P., O'Harte, F. P., and Hewage, C. M. (2007). The bioactive conformation of glucosedependent insulinotropic polypeptide by NMR and CD spectroscopy. Proteins 68, 92-99.

Alken, M., Rutz, C., Kochl, R., Donalies, U., Oueslati, M., Furkert, J., et al. (2005). The signal peptide of the rat corticotropin-releasing factor receptor 1 promotes receptor expression but is not essential for establishing a functional receptor. Biochem. J. 390, 455-464.

Al-Sabah, S., and Donnelly, D. (2003). A model for receptor-peptide binding at the glucagon-like peptide-1 (GLP1) receptor through the analysis of truncated ligands and receptors. $\mathrm{Br}$. J. Pharmacol. 140, 339-346.

Alvarez, E., Martinez, M. D., Roncero, I., Chowen, J. A., Garcia-Cuartero, B., Gispert, J. D., et al. (2005). The expression of GLP-1 receptor mRNA

with conserved residues among the paralogous receptors while the same can be said of conserved residues within orthologous peptides that likely interact with conserved residues within orthologous receptors. Thus, evolutionary conservation across ortholog and specific diversification within paralogs may be required for maintaining the selective interaction of a peptide ligand with its cognate receptor. The crystal structure of ligand-bound GLP1R ECD explains how residues between $\mathrm{Ala}^{18}$ and $\mathrm{Val}^{27}$ interact with the ECD. Biochemical studies using chimeric peptides and receptors reveal receptor contact points only at $\mathrm{His}^{1}$ and $\mathrm{Thr}^{7}$. Thus, the residues between the N-terminus through to position 17 of GLP-1 remain to be explored for their impact on binding to the receptor. Comparative biochemical approaches combined with computeraided molecular modeling will discover additional residues in the peptide and receptor sequences that help understanding the high affinity binding interaction between the ligand-receptor pair.

\section{ACKNOWLEDGMENTS}

This work was supported by grants (2011K00277) from the Brain Research Center of the 21st Century Frontier Research Program, the Brain Research Program of the National Research Foundation of Korea (NRF) funded by the Ministry of Education.

peptide-1: formation of a symmetric helical dimer. FEBS Lett. 515, 165-170.

Chen, Q., Pinon, D. I., Miller, L. J., and Dong, M. (2009). Molecular basis of glucagon-like peptide 1 docking to its intact receptor studied with carboxyl-terminal photolabile probes. J. Biol. Chem. 284, 34135-34144.

Chen, Q., Pinon, D. I., Miller, L. J., and Dong, M. (2010). Spatial approximations between residues 6 and 12 in the amino-terminal region of glucagon-like peptide 1 and its receptor: a region critical for biological activity. J. Biol. Chem. 285, 24508-24518.

Cho, H. J., Acharjee, S., Moon, M. J., Oh, D. Y., Vaudry, H., Kwon, H. B., et al. (2007). Molecular evolution of neuropeptide receptors with regard to maintaining high affinity to their authentic ligands. Gen. Comp. Endocrinol. 153 98-107.

Couvineau, A., Rouyer-Fessard, C., and Laburthe, M. (2004). Presence of a $\mathrm{N}$-terminal signal peptide in class II G protein-coupled receptors: crucial role for expression of the human VPAC1 receptor. Regul. Pept. 123, 181-185.

Dong, M., Li, Z., Zang, M., Pinon, D. I., Lybrand, T. P., and Miller, L. J. (2003). Spatial approximation between two residues in the midregion of secretin and the amino terminus of its receptor. Incorporation of seven sets of such constraints into a three-dimensional model of the agonist-bound secretin receptor. J. Biol. Chem. 278, 48300-48312.

Dong, M., and Miller, L. J. (2002). Molecular pharmacology of the secretin receptor. Recept. Channels 8 , 189-200.

Dong, M., Pinon, D. I., Cox, R. F., and Miller, L. J. (2004). Importance of the amino terminus in secretin family G protein-coupled receptors. Intrinsic photoaffinity labeling establishes initial docking constraints for the calcitonin receptor. $J$. Biol. Chem. 279, 1167-1175.

Drucker, D. J. (2001). Minireview: the glucagon-like peptides. Endocrinology 142, 521-527.

Drucker, D. J. (2003). Glucagon-like peptides: regulators of cell proliferation, differentiation, and apoptosis. Mol. Endocrinol. 17, 161-171.

Drucker, D. J., Philippe, J., Mojsov, S., Chick, W. L., and Habener, J. F. (1987). Glucagon-like peptide I stimulates insulin gene expression and increases cyclic AMP levels in a rat islet cell line. Proc. Natl. Acad. Sci. U.S.A. 84, 3434-3438.

During, M. J., Cao, L., Zuzga, D. S., Francis, J. S., Fitzsimons, H. L., Jiao, X., et al. (2003). Glucagon-like peptide1 receptor is involved in learning and neuroprotection. Nat. Med. 9, 1173-1179.

Fehmann, H. C., and Habener, J. F. (1992). Insulinotropic hormone glucagon-like peptide-I(7-37) stimulation of proinsulin gene expression and proinsulin biosynthesis in insulinoma beta TC-1 cells. Endocrinology 130, 159-166. 
Fehmann, H. C., Hering, B. J., Wolf, M. J., Brandhorst, H., Brandhorst, D., Bretzel, R. G., et al. (1995). The effects of glucagon-like peptide-I (GLP-I) on hormone secretion from isolated human pancreatic islets. Pancreas 11, 196-200.

Gallwitz, B., Witt, M., Paetzold, G., Morys-Wortmann, C., Zimmermann, B., Eckart, K., et al. (1994). Structure/activity characterization of glucagon-like peptide-1. Eur. J. Biochem. 225, 1151-1156.

Gault, V. A., McClean, P. L., Cassidy, R. S., Irwin, N., and Flatt, P. R. (2007). Chemical gastric inhibitory polypeptide receptor antagonism protects against obesity, insulin resistance, glucose intolerance and associated disturbances in mice fed high-fat and cafeteria diets. Diabetologia 50, 1752-1762.

Gensure, R. C., Gardella, T. J., and Juppner, H. (2001). Multiple sites of contact between the carboxylterminal binding domain of PTHrP(1-36) analogs and the aminoterminal extracellular domain of the $\mathrm{PTH} / \mathrm{PTHrP}$ receptor identified by photoaffinity cross-linking. J. Biol. Chem. 276, 28650-28658.

Göke, R., Fehmann, H. C., Linn, T., Schmidt, H., Krause, M., Eng, J., et al. (1993). Exendin-4 is a high potency agonist and truncated exendin-(9-39)-amide an antagonist at the glucagon-like peptide 1(7-36)-amide receptor of insulinsecreting beta-cells. J. Biol. Chem. 268, 19650-19655.

Grace, C. R., Perrin, M. H., DiGruccio, M. R., Miller, C. L., Rivier, J. E., Vale, W. W., et al. (2004). NMR structure and peptide hormone binding site of the first extracellular domain of a type $\mathrm{B} 1 \mathrm{G}$ protein-coupled receptor. Proc. Natl. Acad. Sci. U.S.A. 101, 12836-12841.

Graziano, M. P., Hey, P. J., and Strader, C. D. (1996). The amino terminal domain of the glucagon-like peptide-1 receptor is a critical determinant of subtype specificity. Recept. Channels 4, 9-17.

Gronenborn, A. M., Bovermann, G., and Clore, G. M. (1987). A 1H-NMR study of the solution conformation of secretin. Resonance assignment and secondary structure. FEBS Lett. 215, 88-94.

Hinke, S. A., Gelling, R., Manhart, S., Lynn, F., Pederson, R. A., Kuhn-Wache, K., et al. (2003). Structure-activity relationships of glucose-dependent insulinotropic polypeptide (GIP). Biol. Chem. 384, 403-407.
Hinke, S. A., Kuhn-Wache, K., Hoffmann, T., Pederson, R. A., McIntosh, C. H., and Demuth, H. U. (2002). Metformin effects on dipeptidylpeptidase IV degradation of glucagonlike peptide-1. Biochem. Biophys. Res. Commun. 291, 1302-1308.

Hinke, S. A., Manhart, S., Pamir, N., Demuth, H., Gelling, R. W., Pederson, R. A., et al. (2001). Identification of a bioactive domain in the amino-terminus of glucosedependent insulinotropic polypeptide (GIP). Biochim. Biophys. Acta 1547, 143-155.

Hinke, S. A., Manhart, S., Speck, M., Pederson, R. A., Demuth, H. U., and McIntosh, C. H. (2004). In depth analysis of the N-terminal bioactive domain of gastric inhibitory polypeptide. Life Sci. 75, 1857-1870.

Hisadome, K., Reimann, F., Gribble, F. M., and Trapp, S. (2010). Leptin directly depolarizes preproglucagon neurons in the nucleus tractus solitarius: electrical properties of glucagon-like Peptide 1 neurons. Diabetes 59, 1890-1898.

Hjorth, S. A., and Schwartz, T. W. (1996). Glucagon and GLP-1 receptors: lessons from chimeric ligands and receptors. Acta Physiol. Scand. $157,343-345$.

Holtmann, M. H., Ganguli, S., Hadac, E. M., Dolu, V., and Miller, L. J. (1996). Multiple extracellular loop domains contribute critical determinants for agonist binding and activation of the secretin receptor. J. Biol. Chem. 271, 14944-14949.

Holtmann, M. H., Hadac, E. M., and Miller, L. J. (1995). Critical contributions of amino-terminal extracellular domains in agonist binding and activation of secretin and vasoactive intestinal polypeptide receptors. Studies of chimeric receptors. J. Biol. Chem. 270, 14394-14398.

Hoyle, C. H. (1999). Neuropeptide families and their receptors: evolutionary perspectives. Brain Res. 848, $1-25$.

Huang, Y., Wilkinson, G. F., and Willars, G. B. (2010). Role of the signal peptide in the synthesis and processing of the glucagon-like peptide1 receptor. Br. J. Pharmacol. 159, 237-251.

Inooka, H., Ohtaki, T., Kitahara, O., Ikegami, T., Endo, S., Kitada, C., et al. (2001). Conformation of a peptide ligand bound to its G-protein coupled receptor. Nat. Struct. Biol. 8 , 161-165.

Irwin, D. M. (2001). Molecular evolution of proglucagon. Regul. Pept. 98, 1-12.
Irwin, D. M. (2002). Ancient duplications of the human proglucagon gene. Genomics 79, 741-746.

Irwin, D. M. (2009). Molecular evolution of mammalian incretin hormone genes. Regul. Pept. 155 , 121-130.

Irwin, D. M., and Prentice, K. J. (2011). Incretin hormones and the expanding families of glucagon-like sequences and their receptors. Diabetes Obes. Metab. 13(Suppl. 1) 69-81.

Irwin, D. M., and Wong, K. (2005). Evolution of new hormone function: loss and gain of a receptor. J. Hered. 96, 205-211.

Kieffer, T. J., and Habener, J. F. (1999). The glucagon-like peptides. Endocr. Rev. 20, 876-913.

Kim, D. K., Cho, E. B., Moon, M. J., Park, S., Hwang, J. I., Do Rego, J. L., et al. (2012). Molecular coevolution of neuropeptides gonadotropinreleasing hormone and kisspeptin with their cognate $G$ proteincoupled receptors. Front. Neurosci. 6:3. doi:10.3389/fnins.2012.00003

Kim, D. K., Cho, E. B., Moon, M. J., Park, S., Hwang, J. I., Kah, O., et al. (2011). Revisiting the evolution of gonadotropin-releasing hormones and their receptors in vertebrates: secrets hidden in genomes. Gen. Comp. Endocrinol. 170, 68-78.

Laburthe, M., and Couvineau, A. (2002). Molecular pharmacology and structure of VPAC Receptors for VIP and PACAP. Regul. Pept. 108, 165-173.

Laburthe, M., Couvineau, A., and Tan, V. (2007). Class II G protein-coupled receptors for VIP and PACAP: structure, models of activation and pharmacology. Peptides 28, 1631-1639.

Lee, Y. R., Tsunekawa, K., Moon, M. J., Um, H. N., Hwang, J. I., Osugi, T., et al. (2009). Molecular evolution of multiple forms of kisspeptins and GPR54 receptors in vertebrates. Endocrinology 150, 2837-2846.

Li, J. H., Choe, H., Wang, A. F., Maiti, K., Wang, C., Salam, A., et al. (2005). Extracellular loop 3 (EL3) and EL3proximal transmembrane helix 7 of the mammalian type I and type II gonadotropin-releasing hormone $(\mathrm{GnRH})$ receptors determine differential ligand selectivity to GnRH-I and GnRH-II. Mol. Pharmacol. 67 1099-1110.

Lin, F., and Wang, R. (2009). Molecular modeling of the three-dimensional structure of GLP-1R and its interactions with several agonists. J. Mol. Model. 15, 53-65.

List, J. F., and Habener, J. F. (2004). Glucagon-like peptide 1 agonists and the development and growth of pancreatic beta-cells. Am. J. Physiol. Endocrinol. Metab. 286, E875-E881.

Lopez de Maturana, R., and Donnelly, D. (2002). The glucagon-like peptide1 receptor binding site for the $\mathrm{N}$ terminus of GLP- 1 requires polarity at Asp198 rather than negative charge. FEBS Lett. 530, 244-248.

Lopez de Maturana, R., Treece-Birch, J., Abidi, F., Findlay, J. B., and Donnelly, D. (2004). Met-204 and Tyr-205 are together important for binding GLP1 receptor agonists but not their $\mathrm{N}$-terminally truncated analogues. Protein Pept. Lett. 11, 15-22.

Lopez de Maturana, R., Willshaw, A., Kuntzsch, A., Rudolph, R., and Donnelly, D. (2003). The isolated Nterminal domain of the glucagonlike peptide-1 (GLP-1) receptor binds exendin peptides with much higher affinity than GLP-1. J. Biol. Chem. 278, 10195-10200.

MacDonald, P. E., El-Kholy, W., Riedel, M. J., Salapatek, A. M., Light, P. E., and Wheeler, M. B. (2002). The multiple actions of GLP-1 on the process of glucose-stimulated insulin secretion. Diabetes 51(Suppl. 3), S434S442.

McIntosh, C. H., Widenmaier, S., and Kim, S. J. (2009). Glucosedependent insulinotropic polypeptide (Gastric Inhibitory Polypeptide; GIP). Vitam. Horm. 80, 409-471.

Montrose-Rafizadeh, C., Yang, H., Rodgers, B. D., Beday, A., Pritchette, L. A., and Eng, J. (1997). High potency antagonists of the pancreatic glucagon-like peptide-1 receptor. J. Biol. Chem. 272, 21201-21206.

Moon, M. J., Kim, H. Y., Kim, S. G., Park, J., Choi, D. S., Hwang, J. I., et al. (2010). Tyr1 and Ile7 of glucose-dependent insulinotropic polypeptide (GIP) confer differential ligand selectivity toward GIP and glucagon-like peptide-1 receptors. Mol. Cells 30, 149-154.

Moon, M. J., Kim, H. Y., Park, S., Kim, D. K., Cho, E. B., Hwang, J.-I., et al. (2011). Insulin contributes to finetuning of the pancreatic beta-cell response to glucagon-like peptide-1. Mol. Cells 32, 389-395.

Moon, M. J., Kim, H. Y., Park, S., Kim, D. K., Cho, E. B., Park, C. R., et al. (2012). Evolutionarily conserved residues at glucagon-like peptide-1 (GLP-1) receptor core confer ligandinduced receptor activation. J. Biol. Chem. 287, 3873-3884.

Nauck, M. A., Heimesaat, M. M., Behle, K., Holst, J. J., Nauck, M. S., Ritzel, R., et al. (2002). Effects of glucagon-like peptide 1 on counterregulatory hormone responses, 
cognitive functions, and insulin secretion during hyperinsulinemic, stepped hypoglycemic clamp experiments in healthy volunteers. J. Clin. Endocrinol. Metab. 87, 1239-1246.

Neidigh, J. W., Fesinmeyer, R. M., Prickett, K. S., and Andersen, N. H. (2001). Exendin-4 and glucagon-like-peptide-1: NMR structural comparisons in the solution and micelle-associated states. Biochemistry 40, 13188-13200.

Neumann, J. M., Couvineau, A., Murail, S., Lacapere, J. J., Jamin, N., and Laburthe, M. (2008). Class-B GPCR activation: is ligand helix-capping the key? Trends Biochem. Sci. 33, 314-319.

Oh, D. Y., Song, J. A., Moon, J. S., Moon, M. J., Kim, J. I., Kim, K., et al. (2005). Membrane-proximal region of the carboxyl terminus of the gonadotropin-releasing hormone receptor (GnRHR) confers differential signal transduction between mammalian and nonmammalian GnRHRs. Mol. Endocrinol. 19, 722-731.

Parthier, C., Kleinschmidt, M., Neumann, P., Rudolph, R., Manhart, S., Schlenzig, D., et al. (2007). Crystal structure of the incretin-bound extracellular domain of a $\mathrm{G}$ proteincoupled receptor. Proc. Natl. Acad. Sci. U.S.A. 104, 13942-13947.

Parthier, C., Reedtz-Runge, S., Rudolph, R., and Stubbs, M. T. (2009). Passing the baton in class B GPCRs: peptide hormone activation via helix induction? Trends Biochem. Sci. 34, 303-310.

Perfetti, R., and Merkel, P. (2000). Glucagon-like peptide-1: a major regulator of pancreatic beta-cell function. Eur. J. Endocrinol. 143, 717-725.

Perry, T., Holloway, H. W., Weerasuriya, A., Mouton, P. R., Duffy, K., Mattison, J. A., et al. (2007). Evidence of GLP-1-mediated neuroprotection in an animal model of pyridoxine-induced peripheral sensory neuropathy. Exp. Neurol. 203, 293-301.

Pioszak, A. A., Parker, N. R., Suino-Powell, K., and $\mathrm{Xu}, \mathrm{H}$. E. (2008). Molecular recognition of corticotropin-releasing factor by its G-protein-coupled receptor CRFR1. J. Biol. Chem. 283, 32900-32912.

Pioszak, A. A., and Xu, H. E. (2008). Molecular recognition of parathyroid hormone by its $G$ proteincoupled receptor. Proc. Natl. Acad. Sci. U.S.A. 105, 5034-5039.

Plisetskaya, E. M., and Mommsen, T. P. (1996). Glucagon and glucagon-like peptides in fishes. Int. Rev. Cytol. 168, 187-257.
Runge, S., Thogersen, H., Madsen, K., Lau, J., and Rudolph, R. (2008). Crystal structure of the ligandbound glucagon-like peptide-1 receptor extracellular domain. J. Biol. Chem. 283, 11340-11347.

Runge, S., Wulff, B. S., Madsen, K., Brauner-Osborne, H., and Knudsen, L. B. (2003). Different domains of the glucagon and glucagon-like peptide- 1 receptors provide the critical determinants of ligand selectivity. Br. J. Pharmacol. 138, 787-794.

Sasaki, K., Dockerill, S., Adamiak, D. A., Tickle, I. J., and Blundell, T. (1975). X-ray analysis of glucagon and its relationship to receptor binding. Nature 257, 751-757.

Shen, H. Q., Roth, M. D., and Peterson, R. G. (1998). The effect of glucose and glucagon-like peptide1 stimulation on insulin release in the perfused pancreas in a noninsulin-dependent diabetes mellitus animal model. Metab. Clin. Exp. 47, 1042-1047.

Sherwood, N. M., Krueckl, S. L., and McRory, J. E. (2000). The origin and function of the pituitary adenylate cyclase-activating polypeptide (PACAP)/glucagon superfamily. Endocr. Rev. 21, 619-670.

Stoffers, D. A., Kieffer, T. J., Hussain, M. A., Drucker, D. J., Bonner-Weir, S., Habener, J. F., et al. (2000). Insulinotropic glucagon-like peptide 1 agonists stimulate expression of homeodomain protein IDX-1 and increase islet size in mouse pancreas. Diabetes 49, 741-748.

Stroop, S. D., Kuestner, R. E., Serwold, T. F., Chen, L., and Moore, E. E. (1995). Chimeric human calcitonin and glucagon receptors reveal two dissociable calcitonin interaction sites. Biochemistry 34, 1050-1057.

Sun, C., Song, D., Davis-Taber, R. A., Barrett, L. W., Scott, V. E., Richardson, P. L., et al. (2007). Solution structure and mutational analysis of pituitary adenylate cyclaseactivating polypeptide binding to the extracellular domain of PAC1RS. Proc. Natl. Acad. Sci. U.S.A. 104, 7875-7880.

Tan, Y. V., Couvineau, A., Murail, S., Ceraudo, E., Neumann, J. M., Lacapere, J. J., et al. (2006). Peptide agonist docking in the $\mathrm{N}$-terminal ectodomain of a class II G proteincoupled receptor, the VPAC1 receptor. Photoaffinity, NMR, and molecular modeling. J. Biol. Chem. 281, 12792-12798.

Thorens, B., Porret, A., Buhler, L., Deng, S. P., Morel, P., and Widmann, C. (1993). Cloning and functional expression of the human islet GLP-1 receptor. Demonstration that exendin-4 is an agonist and exendin(9-39) an antagonist of the receptor. Diabetes 42, 1678-1682.

Thornton, K., and Gorenstein, D. G. (1994). Structure of glucagon-like peptide (7-36) amide in a dodecylphosphocholine micelle as determined by 2D NMR. Biochemistry 33 3532-3539.

Underwood, C. R., Garibay, P., Knudsen, L. B., Hastrup, S., Peters, G. H., Rudolph, R., et al. (2010). Crystal structure of glucagon-like peptide1 in complex with the extracellular domain of the glucagon-like peptide-1 receptor. J. Biol. Chem. 285, 723-730

Van Eyll, B., Goke, B., Wilmen, A., and Goke, R. (1996). Exchange of W39 by A within the N-terminal extracellular domain of the GLP-1 receptor results in a loss of receptor function. Peptides 17, 565-570.

Venneti, K. C., and Hewage, C. M. (2011). Conformational and molecular interaction studies of glucagonlike peptide-2 with its N-terminal extracellular receptor domain. FEBS Lett. 585, 346-352.

Vrang, N., Hansen, M., Larsen, P. J., and Tang-Christensen, M. (2007). Characterization of brainstem preproglucagon projections to the paraventricular and dorsomedial hypothalamic nuclei. Brain Res. 1149 118-126.

Wang, C., Yun, O., Maiti, K., Oh, D. Y., Kim, K. K., Chae, C. H., et al. (2004). Position of Pro and Ser near Glu7.32 in the extracellular loop 3 of mammalian and nonmammalian gonadotropin-releasing hormone $(\mathrm{GnRH})$ receptors is a critical determinant for differential ligand selectivity for mammalian $\mathrm{GnRH}$ and chicken GnRH-II. Mol. Endocrinol. 18, 105-116.

Wilmen, A., Goke, B., and Goke, R. (1996). The isolated N-terminal extracellular domain of the glucagon-like peptide-1 (GLP)1 receptor has intrinsic binding activity. FEBS Lett. 398, 43-47.

Wilmen, A., Van Eyll, B., Goke, B. and Goke, R. (1997). Five out of six tryptophan residues in the $\mathrm{N}$ terminal extracellular domain of the rat GLP-1 receptor are essential for its ability to bind GLP-1. Peptides 18 301-305.

Wittelsberger, A., Corich, M., Thomas, B. E., Lee, B. K., Barazza, A., Czodrowski, P., et al. (2006). The mid-region of parathyroid hormone (1-34) serves as a functional docking domain in receptor activation. Biochemistry 45, 2027-2034.

Xiao, Q., Jeng, W., and Wheeler, M. B. (2000). Characterization of glucagon-like peptide-1 receptorbinding determinants. J. Mol. Endocrinol. 25, 321-335.

$\mathrm{Xu}$, G., Stoffers, D. A., Habener, J. F., and Bonner-Weir, S. (1999). Exendin-4 stimulates both betacell replication and neogenesis, resulting in increased beta-cell mass and improved glucose tolerance in diabetic rats. Diabetes 48, 2270-2276.

Yaqub, T., Tikhonova, I. G., Lattig, J., Magnan, R., Laval, M., Escrieut, C., et al. (2010). Identification of determinants of glucose-dependent insulinotropic polypeptide receptor that interact with $\mathrm{N}$-terminal biologically active region of the natural ligand. Mol. Pharmacol. 77, 547-558.

Yeung, C. M., Mojsov, S., Mok, P. Y., and Chow, B. K. (2002). Isolation and structure-function studies of a glucagon-like peptide 1 receptor from goldfish Carassius auratus: identification of three charged residues in extracellular domains critical for receptor function. Endocrinology 143, 4646-4654.

Zander, M., Madsbad, S., Madsen, J. L., and Holst, J. J. (2002). Effect of 6week course of glucagon-like peptide 1 on glycaemic control, insulin sensitivity, and beta-cell function in type 2 diabetes: a parallel-group study. Lancet 359, 824-830.

Conflict of Interest Statement: The authors declare that the research was conducted in the absence of any commercial or financial relationships that could be construed as a potential conflict of interest.

Received: 04 September 2012; paper pending published: 24 September 2012; accepted: 29 October 2012; published online: 19 November 2012.

Citation: Moon MJ, Park S, Kim D$K$, Cho EB, Hwang J-I, Vaudry $H$ and Seong JY (2012) Structural and molecular conservation of glucagon-like peptide1 and its receptor confers selective ligandreceptor interaction. Front. Endocrin. 3:141. doi: 10.3389/fendo.2012.00141

This article was submitted to Frontiers in Neuroendocrine Science, a specialty of Frontiers in Endocrinology.

Copyright $(2012$ Moon, Park, Kim, Cho, Hwang, Vaudry and Seong. This is an open-access article distributed under the terms of the Creative Commons Attribution License, which permits use, distribution and reproduction in other forums, provided the original authors and source are credited and subject to any copyright notices concerning any third-party graphics etc. 